\title{
BMJ Open Association of body mass index and age with incident diabetes in Chinese adults: a population-based cohort study
}

\author{
Ying Chen, ${ }^{1,2}$ Xiao-Ping Zhang, ${ }^{3}$ Jie Yuan, ${ }^{1}$ Bo Cai, ${ }^{4}$ Xiao-Li Wang, ${ }^{3}$ Xiao-Li Wu, ${ }^{3}$ \\ Yue-Hua Zhang, ${ }^{3}$ Xiao-Yi Zhang, ${ }^{1}$ Tong Yin, ${ }^{1}$ Xiao-Hui Zhu, ${ }^{1}$ Yun-Juan Gu, ${ }^{1}$ \\ Shi-Wei Cui, ${ }^{1}$ Zhi-Qiang Lu, ${ }^{2}$ Xiao-Ying Li ${ }^{2}$
}

To cite: Chen Y, Zhang X-P, Yuan J, et al. Association of body mass index and age with incident diabetes in Chinese adults: a population-based cohort study. BMJ Open 2018;8:e21768. doi:10.1136 bmjopen-2018-021768

- Prepublication history and additional material for this paper are available online. To view these files, please visit the journal online (http://dx.doi. org/10.1136/bmjopen-2018021768).

YC, X-PZ and JY contributed equally.

S-WC, Z-QL and X-YL contributed equally.

Received 26 January 2018 Revised 3 May 2018 Accepted 25 Julv 2018

A) Check for updates

(C) Author(s) (or their employer(s)) 2018. Re-use permitted under CC BY-NC. No commercial re-use. See rights and permissions. Published by BMJ.

${ }^{1}$ Department of Endocrinology and Metabolism, Affiliated Hospital of Nantong University, Nantong, China

${ }^{2}$ Department of Endocrinology and Metabolism, Zhongshan Hospital, Fudan University, Shanghai, China

${ }^{3}$ Department of Health Examination, Rich Healthcare Group, Shanghai, China ${ }^{4}$ Nantong Center for Chronic and Noncommunicable Disease Control and Prevention, Center for Disease Control and Prevention, Nantong, China

Correspondence to Professor Xiao-Ying Li; lixy@sibs.ac.cn

\section{ABSTRACT}

Objective Type 2 diabetes mellitus is increasing in young adults, and greater adiposity is considered a major risk factor. However, whether there is an association between obesity and diabetes and how this might be impacted by age is not clear. Therefore, we investigated the association between body mass index (BMI) and diabetes across a wide range of age groups (20-30, 30-40, 40-50, 50-60, $60-70$ and $\geq 70$ years old).

Design We performed a retrospective cohort study using healthy screening programme data.

Setting A total of 211833 adult Chinese persons $>20$ years old across 32 sites and 11 cities in China (Shanghai, Beijing, Nanjing, Suzhou, Shenzhen, Changzhou, Chengdu, Guangzhou, Hefei, Wuhan, Nantong) were selected for the study; these persons were free of diabetes at baseline.

Primary and secondary outcome measures Fasting plasma glucose levels were measured and information regarding the history of diabetes was collected at each visit. Diabetes was diagnosed as fasting plasma glucose $\geq 7.00 \mathrm{mmol} / \mathrm{L}$ and/or self-reported diabetes. Patients were censored at the date of diagnosis or the final visit, whichever came first.

Results With a median follow-up of 3.1 years, 4174 of the 211833 participants developed diabetes, with an age-adjusted incidence rate of 7.35 per 1000 persons. The risk of incident diabetes increased proportionally with increasing baseline BMl values, with a $23 \%$ increased risk of incident diabetes with each $\mathrm{kg} / \mathrm{m}^{2}$ increase in BMl $(95 \% \mathrm{Cl} 1.22$ to 1.24). Across all age groups, there was a linear association between BMI and the risk of incident diabetes, although there was a stronger association between $\mathrm{BMI}$ and incident diabetes in the younger age groups (age $\times \mathrm{BMl}$ interaction, $\mathrm{p}<0.0001$ ).

Conclusions An increased BMI is also independently associated with a higher risk of developing diabetes in young adults and the effects of BMI on incident diabetes were accentuated in younger adults.

\section{INTRODUCTION}

Type 2 diabetes is a global epidemic. The International Diabetes Federation estimates that about 415 million people worldwide had type 2 diabetes mellitus (T2DM) in 2015. This number is expected to rise to
Strengths and limitations of this study

The large sample size allows analysis of the interaction of age and body mass index on incident diabetes.

- Our study was composed of young, middle and oldaged apparently healthy adults, while participants in many other cohorts tended to be older.

- The data were collected under standardised conditions and followed according to uniform procedures by trained staff. Laboratory methods also were carefully standardised with rigorous internal and external quality controls.

- We only measured body weight and height at baseline, which could not address fat distribution and weigh change.

642 million by 2040 , with 140.2 million of the affected people living in Asia. ${ }^{1}$ Although diabetes has traditionally been thought of as a disease that affects elderly people, the prevalence of type 2 diabetes in young adults is increasing. National surveys in China report that $7.09 \%$ of the individuals that had developed diabetes were younger than 40 years in 2011, while this percentage was less than $1 \%$ two decades ago. ${ }^{2}$ Younger patients with diabetes tend to have a poorer prognosis, associated with an increased risk of cardiovascular disease and microvascular complications. ${ }^{34}$ The reasons for the declining age at the onset of type 2 diabetes are poorly understood and complicated. However, it has been speculated that the increasing prevalence of obesity in younger individuals may contribute to the epidemic of diabetes in young people. ${ }^{5}$

Greater adiposity is a major risk factor for the development of type 2 diabetes. A meta-analysis combining 18 prospective cohort studies reported that the relative risk (RR) of diabetes for obese persons compared with those with normal weight was 7.19 (95\% CI 5.74 to 9.00 ) and compared with 
overweight individuals was 2.99 (95\% CI 2.42 to 3.72 ). ${ }^{6}$ Obesity and diabetes are so interconnected that the term 'diabesity' has been coined. ${ }^{7}$ However, there also seems to be an important relationship with age. ${ }^{8}{ }^{9}$ Younger age itself is a protective factor for incident diabetes; for every 10 years younger a person is, the risk of developing diabetes decreases by $50 \%-70 \% .{ }^{10}$ However, the increasing prevalence of obesity in young individuals seems to weaken the protective effects of age, in regard to diabetes incidence. The Non-communicable Disease Risk Factor Collaboration (NCD-RisC) pooled 128.9 million children, adolescents and adults to assess worldwide trends in body mass index (BMI), looking at underweight, overweight and obese individuals from 1975 to 2016 and found that the mean BMI and obesity prevalence in adolescents and young adults has risen in past decades, and the trend is still continuing. ${ }^{11}$ However, the relationship between age, BMI and diabetes incidence remains unclear. The risk of mortality per unit increase in BMI is greater in younger than in older people. ${ }^{12}$ However, the effect of age on the association between BMI and kidney disease is the opposite. ${ }^{13}$ The heterogeneity of the association between diabetes and age has been seldom explored. The Asia Pacific Cohort Studies Collaboration pooled 27 cohorts from Asia, New Zealand and Australia found that the association between BMI and the risk of diabetes was stronger in participants under 60 compared with individuals between 60 and 69 years of age, while the association was lowest in patients $>70$ years old. ${ }^{14}$ However, these conclusions were based on an older population where most adults were older than 40 years old. Whether these findings can be extrapolated to younger adults is unclear, despite the increasing risk of type 2 diabetes in younger individuals. Therefore, in the present study, we investigated the association between BMI and the risk of incident diabetes in a large retrospective cohort of individuals ranging from 20 to 99 years old.

\section{METHODS}

\section{Study design and participants}

Data were extracted from a computerised database established by the Rich Healthcare Group in China, which includes all medical records for participants who received a health check from 2010 to 2016 . The present analysis initially included all study participants who were at least 20 years old with at least two visits between 2010 and 2016 $(n=685277)$. Participants were excluded at baseline if they had no available weight and height measurements $(\mathrm{n}=103946)$, no available information on gender $(\mathrm{n}=1)$, extreme BMI values $\left(<15 \mathrm{~kg} / \mathrm{m}^{2}\right.$ or $\left.>55 \mathrm{~kg} / \mathrm{m}^{2}\right) \quad(\mathrm{n}=152)$ or no available fasting plasma glucose value $(\mathrm{n}=31370)$. We further excluded participants with visit intervals less than 2years $(n=324233)$, participants diagnosed with diabetes at baseline (2997 participants diagnosed by self-report and 4115 diagnosed by a fasting plasma glucose $\geq 7.0 \mathrm{mmol} / \mathrm{L}$ ), and participants with undefined diabetes status at follow-up $(\mathrm{n}=6630)$. Finally, a total of
211833 participants (116123 male and 95710 female) were included in the analysis. Cohort entry was defined as the date of the initial visit. Compared with individuals excluded from the present analyses, those included in the analyses were with similar age (42.1 vs 41.9 years old) and similar BMI (23.2 vs $23.3 \mathrm{~kg} / \mathrm{m}^{2}$ ), and with a relatively higher proportion of males ( $54.8 \%$ vs $52.1 \%$ ).

In each visit to the health check centre, participants were requested to complete a detailed questionnaire assessing demographic, lifestyle, medical history and family history of chronic disease. Height, weight and blood pressure were measured by trained staff. Body weight was measured in light clothing with no shoes to the nearest $0.1 \mathrm{~kg}$. Height was measured to the nearest $0.1 \mathrm{~cm}$. BMI was derived from weight in kilograms divided by height in metres squared. Blood pressure was measured by standard mercury sphygmomanometers.

Fasting venous blood samples were collected after at least a 10 hours fast at each visit. Serum triglyceride (TG), total cholesterol, low-density lipoprotein cholesterol (LDL-C) and high-density lipoprotein cholesterol were measured on an autoanalyzer (Beckman 5800). Plasma glucose levels were measured by the glucose oxidase method on an autoanalyzer (Beckman 5800).

\section{Ascertainment of incident diabetes}

Diagnosis of incident diabetes was defined as fasting plasma glucose of $\geq 7.00 \mathrm{mmol} / \mathrm{L}$ and/or self-reported diabetes during the follow-up period. Patients were censored at the date of diagnosis of diabetes or the final visit, whichever came first.

\section{Statistical analysis}

Statistical analyses were performed on SAS V.9.3 (SAS Institute). A two-sided $p$ value less than 0.05 was considered statistically significant. Data from descriptive analyses were reported as mean (SD) or median (IQR), or proportions. Participants were stratified into six baseline age groups with 10-year increments starting from 20 to 30 years old to over 70 years old. Linear regression models were performed to assess the relationship between BMI, metabolic parameters, lifestyles and family history of diabetes with age. Diabetes incidence was calculated in each and in the total of all age groups, and age-standardised diabetes incidence was adjusted to the Chinese population in $2010 .^{15}$

Cox proportional hazard regression models were performed to estimate BMI-adjusted and multivariable-adjusted HRs (95\% CIs) of age with incident diabetes and age-adjusted and multivariable-adjusted HRs (95\% CIs) of BMI with incident diabetes. Analyses of BMI used predefined standard categories according to the Chinese criteria of obesity ${ }^{16}$ : underweight $(<18.5 \mathrm{~kg} /$ $\mathrm{m}^{2}$ ), normal weight $\left(18.5\right.$ to $\left.<24.0 \mathrm{~kg} / \mathrm{m}^{2}\right)$, overweight $\left(24.0\right.$ to $\left.<28.0 \mathrm{~kg} / \mathrm{m}^{2}\right)$ and obese $\left(\geq 28.0 \mathrm{~kg} / \mathrm{m}^{2}\right)$. The normal BMI group (18.5 to $<24.0 \mathrm{~kg} / \mathrm{m}^{2}$ ) was chosen as the referent category. Covariates in the multivariable models included age, sex, smoking status, drinking status 
and family history of diabetes. The association between BMI and incident diabetes, as influenced by age, was further investigated. HRs of incident diabetes were calculated, respectively, in each age group by Cox proportional hazard regression models with a BMI of 18.5 to $<24.0 \mathrm{~kg} /$ $\mathrm{m}^{2}$ as the reference category. Since the association between BMI and incident diabetes was approximately linear, the HRs and corresponding 95\% CI for incident diabetes across all age groups were estimated for per $\mathrm{kg} /$ $\mathrm{m}^{2}$ increase in BMI value. The modification effect was assessed for the interaction of age and BMI in the Cox model.

In consideration of the baseline, confounding factors including smoking status and family history of diabetes related to diabetes in young adults, subgroup analyses were further performed respective to the HR of smoking status and family history of diabetes, in regard to the overall risk of diabetes. The interaction of BMIxcurrent smoker, agexfamily history of diabetes was assessed in the Cox model.

\section{Patient and public involvement}

Given the retrospective nature of the study, no patients were involved in any aspect of the study.

\section{RESULTS}

A total of 211833 participants (116123 male and 95710 female) without diabetes at baseline were recruited. The mean age was 42.1 years old (SD 12.6), ranging from 20 to 99 years old. The mean BMI value was $23.2 \mathrm{~kg} / \mathrm{m}^{2}$ (SD 3.3). Baseline clinical and biochemical characteristics of participants were stratified by age and sex, BMI and sex are presented in table 1 and online supplementary table 1. Total serum cholesterol, TG, LDL-C, fasting plasma glucose, systolic blood pressure and diastolic blood pressure gradually increased with age and BMI in both men and women.

During a median of 3.1-year follow-up (660 191 personyears), 4174 of 211833 participants developed diabetes. The incidence of diabetes was 7.35 per 1000 person-years with age-standardisation (table 2). The risk of incident diabetes increased proportionally with age and BMI values (table 2). For every 10 years of increasing age, the HR of developing diabetes increased by $88 \%$ (95\% CI 1.85 to 1.92 ). Using participants ages $20-30$ years old as the reference, the BMI-adjusted HR for incident diabetes was 1.64 (95\% CI 1.29 to 2.09 ) in participants ages 30-40 years old, 3.83 (95\% CI 3.03 to 4.86) in participants ages $40-50$ years old, 8.39 (95\% CI 6.64 to 10.59 ) in participants ages 50-60years old, 11.77 (95\% CI 9.30 to 14.89 ) in participants ages $60-70$ years old and 17.55 (95\% CI 13.79 to 22.33 ) in participants $\geq 70$ years old. Using participants with a BMI of 18.5 to $<24.0 \mathrm{~kg} / \mathrm{m}^{2}$ as reference, the age-adjusted HR for incident diabetes was 0.39 (95\% CI 0.27 to 0.56 ) in participants with a BMI of $<18.5 \mathrm{~kg} / \mathrm{m}^{2}$, $2.51(95 \%$ CI 2.33 to 2.70$)$ with a BMI of $24.0-27.9 \mathrm{~kg} / \mathrm{m}^{2}$ and 5.58 (95\% CI 5.13 to 6.07 ) with a BMI of $\geq 28.0 \mathrm{~kg} /$ $\mathrm{m}^{2}$. Further adjustment for sex, smoking status, drinking status and family history of diabetes did not alter the trend appreciably.

Sex-adjusted HRs (95\% CI) of BMI for risk of incident diabetes are shown in figure 1 and online supplementary table 2. Using participants with a BMI of 18.5 to $<24.0 \mathrm{~kg} /$ $\mathrm{m}^{2}$ as the reference, the age-adjusted HR for incident diabetes in overweight and obese individuals was higher at younger ages than older ages. The linear association between BMI and risk of incident diabetes was present in participants across all age groups. When BMI was analysed as a continuous variable, the sex-adjusted HR of developing diabetes was 1.23 (95\% CI 1.22 to 1.24) for each $\mathrm{kg} / \mathrm{m}^{2}$ increase in BMI. A stronger association between BMI and incident diabetes was shown in the youngest age group (table 3). The risk of incident diabetes was increased by $35 \%$ (95\% CI $1.29 \%$ to $1.40 \%$ ) for each $\mathrm{kg} /$ $\mathrm{m}^{2}$ increase of BMI in the group of 20-30years old, $31 \%$ (95\% CI $1.29 \%$ to $1.33 \%$ ) in the group of $30-40$ years old, $27 \%$ (95\% CI $1.25 \%$ to $1.29 \%$ ) in the group of $40-50$ years old, $18 \%$ (95\% CI $1.17 \%$ to $1.20 \%)$ in the group of $50-60$ years old, $13 \%$ (95\% CI $1.11 \%$ to $1.15 \%$ ) in the group of $60-70$ years old and $11 \%$ (95\% CI $1.08 \%$ to $1.14 \%)$ in the group of greater than 70 years old. The descending trend by age remained separately in men and women, and was not altered by further adjustment for smoking status, drinking status and family history of diabetes. Obviously, age significantly modified the association between BMI and the risk of incident diabetes (age $\times$ BMI interaction, $\mathrm{p}<0.0001$ ).

Current smokers were at a decreased risk of incident diabetes (HR 0.79 ; $95 \%$ CI 0.74 to 0.84 ), and participants with a family history of diabetes were at an increased risk of incident diabetes (HR 1.68; 95\% CI 1.38 to 2.03). The multiplicative interactions of BMI $\times$ smoking status ( $\mathrm{p}$ for interaction $=0.25)$ and age $\times$ family history of diabetes $(p$ for interaction $=0.71$ ) in regard to the risk of incident diabetes were not significant (online supplementary table 3).

\section{DISCUSSION}

In the present cohort, an age-standardised diabetes incidence of 7.35 per 1000 person-years during 2010-2016 was detected. We demonstrated a linear association between baseline BMI and the risk of developing diabetes, which increased with each $\mathrm{kg} / \mathrm{m}^{2}$ of BMI, associated with $23 \%$ (95\% CI $1.22 \%$ to $1.24 \%$ ) higher risk of incident diabetes. The risk of incident diabetes was increased by $35 \%$ (95\% CI $1.29 \%$ to $1.40 \%$ ) for each $\mathrm{kg} / \mathrm{m}^{2}$ increase of BMI in the group of 20-30years old and $31 \%(95 \%$ CI $1.29 \%$ to $1.33 \%$ ) in the group of $30-40$ years old. However, the risk of incident diabetes was slightly lower in the group of 40-50, 50-60 and 60-70years old: 1.27 (95\% CI 1.25 to 1.29 ), 1.18 (95\% CI 1.17 to 1.20 ) and 1.13 (95\% CI 1.11 to 1.15), respectively. Again, the HR of incident diabetes was the lowest in the group of 70 years old at 1.11 (95\% CI 1.08 to 1.14). Further analyses 


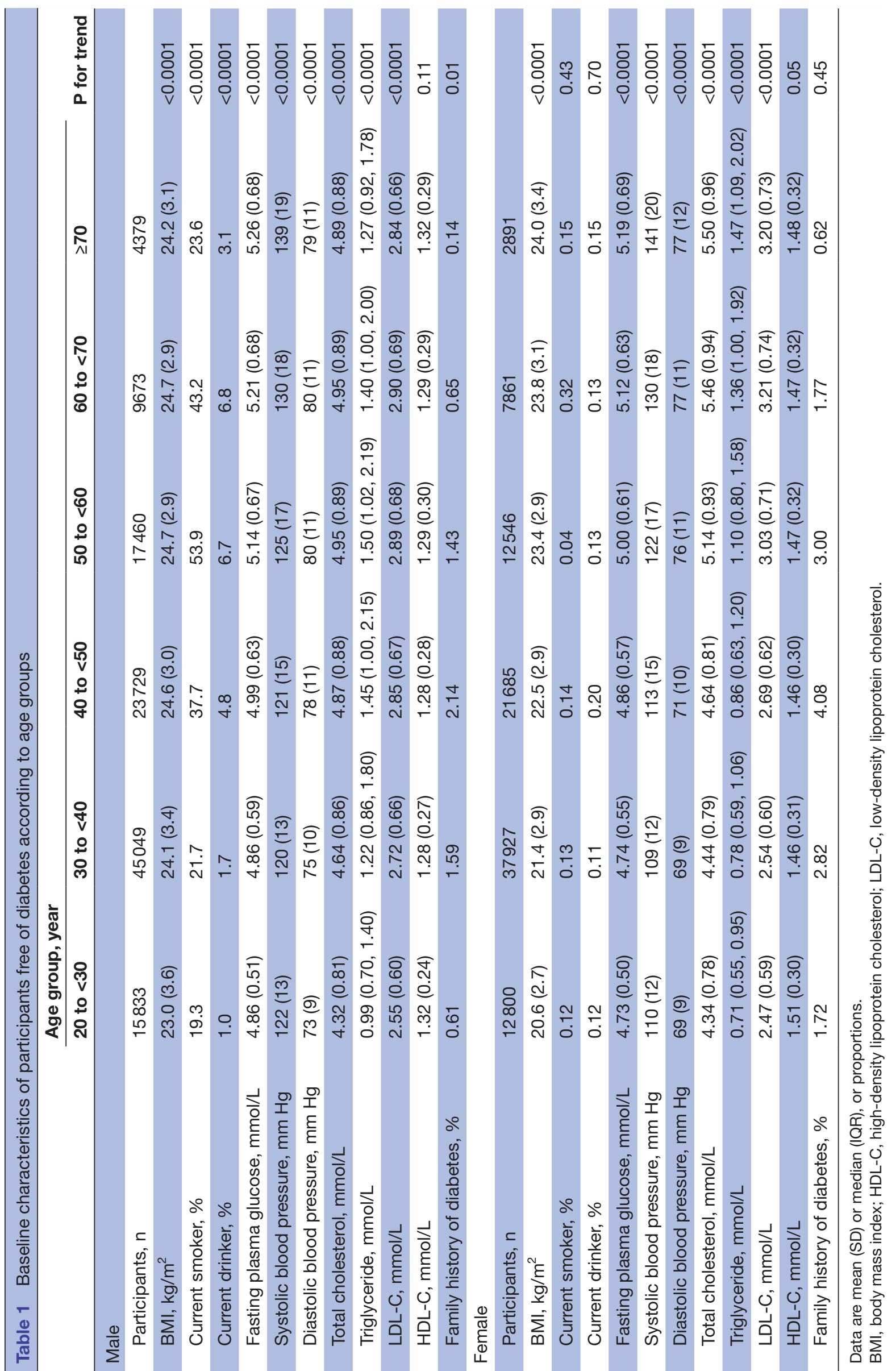


Table 2 Association between age and body mass index with risk of incident diabetes in Chinese adults

\begin{tabular}{|c|c|c|c|c|c|}
\hline \multirow[b]{2}{*}{ Age, year } & \multirow[b]{2}{*}{ Participants (n) } & \multirow[b]{2}{*}{ Events (n) } & \multirow{2}{*}{$\begin{array}{l}\text { Incidence rate } \\
\text { (per } 1000 \text { persons } \\
\text { per year) }\end{array}$} & \multicolumn{2}{|l|}{ HRs } \\
\hline & & & & $\begin{array}{l}\text { Body mass } \\
\text { index adjusted }\end{array}$ & $\begin{array}{l}\text { Multivariable adjusted } \\
\text { +body mass index }\end{array}$ \\
\hline 20 to $<30$ & 28633 & 75 & 0.93 & Ref. & Ref. \\
\hline 30 to $<40$ & 82976 & 546 & 2.18 & $1.64(1.29,2.09)$ & $2.07(1.24,3.47)$ \\
\hline 40 to $<50$ & 45414 & 789 & 5.45 & $3.83(3.03,4.86)$ & $4.83(2.90,8.03)$ \\
\hline 50 to $<60$ & 30006 & 1224 & 12.50 & $8.39(6.64,10.59)$ & $12.26(7.42,20.27)$ \\
\hline 60 to $<70$ & 17534 & 976 & 17.61 & $11.77(9.30,14.89)$ & $15.50(9.34,25.70)$ \\
\hline$\geq 70$ & 7270 & 564 & 22.39 & $17.55(13.79,22.33)$ & $21.98(13.14,36.77)$ \\
\hline $\mathrm{P}$ for trend & - & - & - & $<0.0001$ & $<0.0001$ \\
\hline Crude rate & 211833 & 4174 & 6.17 & - & - \\
\hline Standardised rate & 211833 & 4174 & 7.35 & - & - \\
\hline Body mass index, $\mathrm{kg} / \mathrm{m}^{2}$ & & & & Age adjusted & Multivariable adjusted \\
\hline$<18.5$ & 12081 & 31 & 0.82 & $0.39(0.27,0.56)$ & $0.46(0.24,0.90)$ \\
\hline 18.5 to $<24.0$ & 116812 & 1073 & 2.72 & Ref. & Ref. \\
\hline 24.0 to $<28.0$ & 64774 & 1936 & 9.44 & $2.51(2.33,2.70)$ & $2.36(2.04,2.73)$ \\
\hline$\geq 28.0$ & 18166 & 1134 & 21.00 & $5.58(5.13,6.07)$ & $5.22(4.44,6.13)$ \\
\hline$P$ for trend & & & & $<0.0001$ & $<0.0001$ \\
\hline
\end{tabular}

Multivariable-adjusted model adjusted for age, sex, smoking status, drinking status, family history of diabetes.

*The incidence rate was standardised to the population of mainland China in 2010.

showed that age had a modifying effect on this association. Overall, the effect of BMI on incident diabetes was stronger in younger adults. Subgroup analyses showed that the interactions between BMI and smoking status or age and family history of diabetes, in regard to the risk of incident diabetes, were not significant.

Our study reported an age-standardised diabetes incidence of 7.35 per 1000 person-years during 2010-2016. With lifestyle changes, the prevalence of type 2 diabetes has increased rapidly in the past decades in China. Data from the national surveys show that the prevalence of diabetes was $0.9 \%$ in $1980,{ }^{17} 2.5 \%$ in $1994,{ }^{18} 9.7 \%$ in $2007^{19}$ and $10.9 \%$ in $2013 .{ }^{20}$ However, the incidence of diabetes appears to have stabilised and there have been small declines from 2007 to $2014,{ }^{21}$ which is not consistent with the prevalence trend. Based on our large sample cohort, the incidence of diabetes increased by 7.35 per 1000 person-years between 2010 and 2016. All diabetes diagnoses were based on a self-reported diagnosis of diabetes and/or a fasting glucose level equal to or greater than $7.0 \mathrm{mmol} / \mathrm{L}$. As such, we could have missed some cases of type 2 diabetes. The Diabetes Epidemiology Collaborative Analysis of Diagnostic Criteria in Europe and Asia studies show that fasting glucose alone only detected about $68 \%$ of new patients with diabetes in Europe ${ }^{22}$ and $55 \%$ of new patients with diabetes in Asia. ${ }^{23}$ And national surveys have reported $46.6 \%$ of Chinese with undiagnosed diabetes had isolated increased 2-hour plasma glucose after an oral glucose tolerance test. Therefore, the true estimated incidence of diabetes should be higher than the data from this study. However, oral glucose tolerance tests are not applicable for large sample survey due to its complexity to operate.

Obesity is the major risk factor for diabetes development. Hartemink et al conducted a meta-analyses that detected a dose-response relationship between BMI and type 2 diabetes. It was shown that per $\mathrm{kg} / \mathrm{m}^{2}$ increase in BMI, the risk of diabetes increased by $18 \%$ (95\% CI $1.16 \%$ to $1.20 \%$ ), accounting for the heterogeneity among studies. ${ }^{24}$ The aetiological effects of BMI have mostly been extrapolated from the European population, while Chinese individuals tend to have a higher incidence of diabetes and related risk factors per unit increase in BMI. ${ }^{25}{ }^{26}$ In the present study, the age-adjusted HR for incident diabetes was 2.51 (95\% CI 2.33to 2.70) in overweight individuals with a BMI of $24.0-27.9 \mathrm{~kg} / \mathrm{m}^{2}$ and 5.58 (95\% CI 5.13 to 6.07$)$ in obese individuals with a BMI of $\geq 28.0 \mathrm{~kg} / \mathrm{m}^{2}$, compared with normal weight individuals with a BMI of 18.5 to $<24.0 \mathrm{~kg} / \mathrm{m}^{2}$. Our HR of diabetes incidence per $\mathrm{kg} / \mathrm{m}^{2}$ increase in BMI was $1.23(95 \% \mathrm{CI}$ 1.22 to 1.24 ), which was slightly higher than previously reported. ${ }^{24}$ Moreover, it was interesting to find that the HR was significantly higher in younger adults less than 40 years old.

Young age itself is a remarkable protective factor for developing diabetes. While most of the increase in the prevalence of T2DM has been seen in the middle aged and elderly, there is strong evidence that it is becoming more common among young adults. The increasing prevalence of obesity in young individuals has been speculated to at least partly explain the increasing prevalence of diabetes in young adults. However, the available data on diabetes 

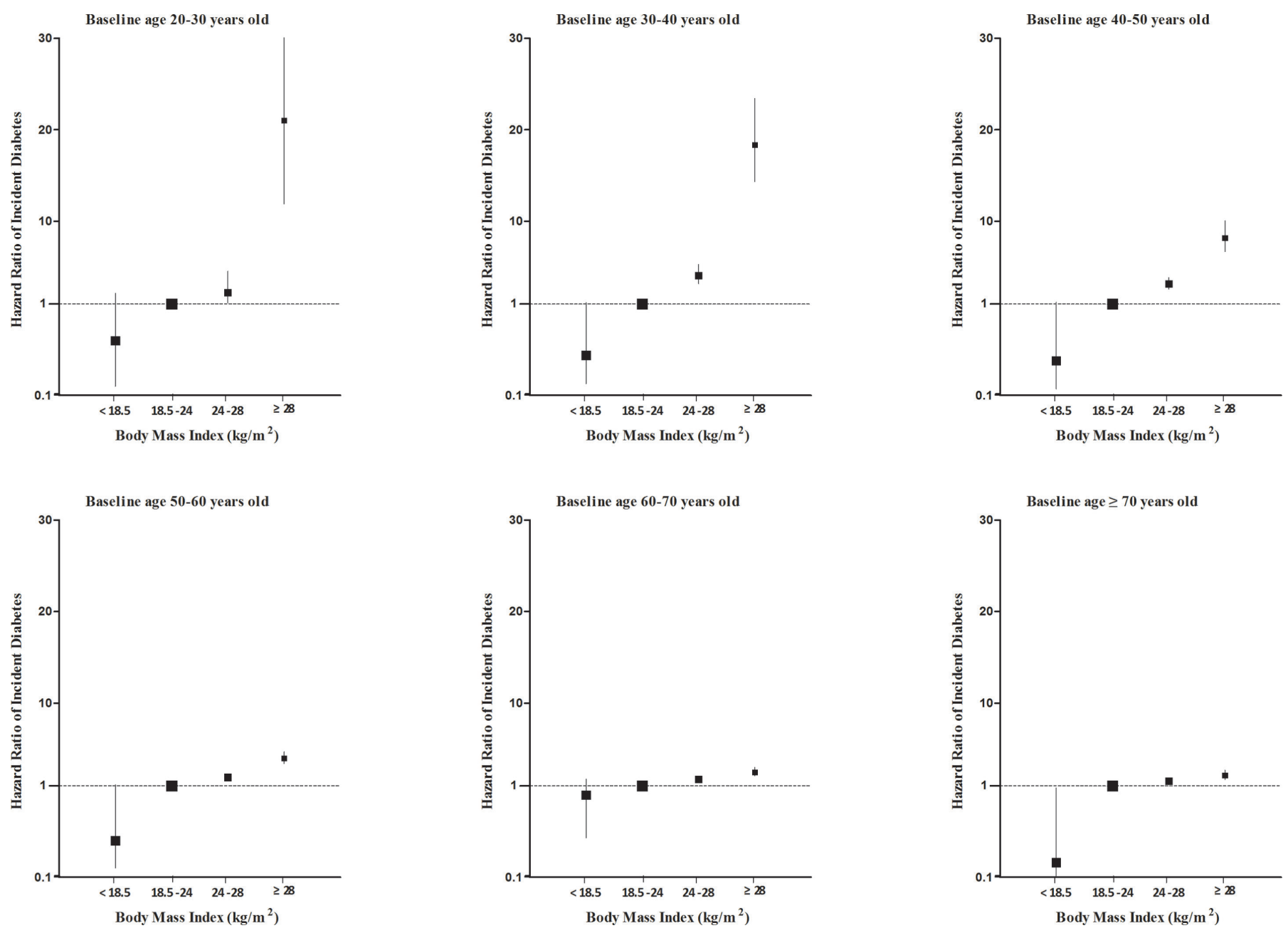

Figure 1 Association of BMI with risk of incident diabetes, by baseline age group. A BMI of $18.5-23.9 \mathrm{~kg} / \mathrm{m}^{2}$ was defined as the referent category. BMI, body mass index.

in younger populations are limited. Recent studies have shown that the association between BMI and its outcomes more significantly varied in younger versus older adults. The global BMI mortality collaboration, including 239 prospective studies in four continents, found that the risk of mortality per unit increase in BMI was greater in younger than in older people. ${ }^{12}$ However, the effect of age on the association between BMI and kidney disease appears to be the opposite. ${ }^{13}$ The heterogeneity of age on the association of obesity and type 2 diabetes has been assessed in only a few studies with inconsistent results. Data from the Third National Health and Nutrition Examination Survey showed that BMI was strongly associated with an increased RR of developing a metabolic disorder, including type 2 diabetes and cardiovascular diseases. Furthermore, the association between BMI and cardiovascular disease and hypertension was reduced with increasing age. However, any modifying effects of age on the association between BMI and type 2 diabetes were not detected. ${ }^{27}$ Meta-analysis data from Japan, Australia and New Zealand demonstrated a stronger association between BMI and the risk of diabetes in subjects younger than 60 years old compared with people older than 70 years old. ${ }^{28}$ However, most of the persons included in this study were older than 40 years old. The limited sample size and age range might contribute to this disparity. Avoiding these factors, we found a generally consistent linear association between BMI and incident diabetes that weakened with advancing age. BMI had a much greater risk on incident diabetes in earlier adulthood than in later adulthood, which was consistent with the findings from a meta-analysis conducted by $\mathrm{Ni}$ Mhurchu et $a l^{28}$ which extends this finding to adults younger than 40 years old.

The mechanism(s) responsible for the heterogeneity of BMI effect in regard to age are unclear. Young-onset obesity has been reported to have more genetic predisposition to metabolic disorders, and resulted in chronically increased levels of circulating free fatty acids and adipokines, which reduced insulin sensitivity and might contribute to increased reactive oxygen species and impaired insulin secretion. ${ }^{29}{ }^{30}$ Furthermore, young-onset obesity patients might have an early life exposure to maternal undernutrition or overnutrition, which is associated with an increased risk of type 2 diabetes. ${ }^{31} 32$ And individuals with young-onset obesity tend to have a detrimental/inactive 
Table 3 Association of per $\mathrm{kg} / \mathrm{m}^{2}$ increase of body mass index and incident diabetes, by baseline age group

\begin{tabular}{|c|c|c|}
\hline \multirow[b]{2}{*}{ Age, year } & \multicolumn{2}{|l|}{ HR } \\
\hline & Sex adjusted & Multivariable adjusted \\
\hline 20 to $<30$ & $1.35(1.29,1.40)$ & $1.39(1.27,1.52)$ \\
\hline 30 to $<40$ & $1.31(1.29,1.33)$ & $1.30(1.26,1.34)$ \\
\hline 40 to $<50$ & $1.27(1.25,1.29)$ & $1.27(1.23,1.32)$ \\
\hline 50 to $<60$ & $1.18(1.17,1.20)$ & $1.17(1.13,1.21)$ \\
\hline 60 to $<70$ & $1.13(1.11,1.15)$ & $1.14(1.10,1.19)$ \\
\hline$\geq 70$ & $1.11(1.08,1.14)$ & $1.12(1.07,1.17)$ \\
\hline AgexBMl interaction, $\mathrm{p}$ & $<0.0001$ & $<0.0001$ \\
\hline Age, year & Non-adjusted & Multivariable adjusted \\
\hline \multicolumn{3}{|l|}{ Male } \\
\hline 20 to $<30$ & $1.37(1.31,1.44)$ & $1.41(1.29,1.55)$ \\
\hline 30 to $<40$ & $1.31(1.29,1.34)$ & $1.30(1.26,1.35)$ \\
\hline 40 to $<50$ & $1.26(1.23,1.28)$ & $1.25(1.20,1.30)$ \\
\hline 50 to $<60$ & $1.18(1.16,1.21)$ & $1.17(1.13,1.21)$ \\
\hline 60 to $<70$ & $1.14(1.11,1.17)$ & $1.17(1.11,1.23)$ \\
\hline$\geq 70$ & $1.13(1.09,1.17)$ & $1.16(1.10,1.24)$ \\
\hline AgexBMl interaction, $\mathrm{P}$ & $<0.0001$ & 0.0004 \\
\hline \multicolumn{3}{|l|}{ Female } \\
\hline 20 to $<30$ & $1.29(1.19,1.40)$ & $1.31(1.21,1.43)$ \\
\hline 30 to $<40$ & $1.30(1.26,1.34)$ & $1.30(1.26,1.35)$ \\
\hline 40 to $<50$ & $1.31(1.26,1.35)$ & $1.29(1.24,1.34)$ \\
\hline 50 to $<60$ & $1.19(1.15,1.22)$ & $1.18(1.15,1.21)$ \\
\hline 60 to $<70$ & $1.12(1.09,1.15)$ & $1.12(1.08,1.16)$ \\
\hline$\geq 70$ & $1.09(1.05,1.13)$ & $1.09(1.05,1.14)$ \\
\hline AgexBMl interaction, $p$ value & $<0.0001$ & $<0.0001$ \\
\hline
\end{tabular}

Multivariable-adjusted model adjusted for sex, smoking status, drinking status, family history of diabetes.

BMI, body mass index.

lifestyle, which might also contribute to the development of adiposity, insulin resistance, hyperglycaemia and other cardiovascular risk factors. ${ }^{33} 34$ Therefore, obese youth lose the protective effects of a young age in regard to diabetes risk. On the other side, weight consists of fat and muscle. The decrease in body weight by increasing age can be explained by the process of sarcopenia with significant decreases in muscle mass combined with slightly increases in fat mass. ${ }^{35}$ An additional process associated with ageing is fat redistribution. Subcutaneous fat, which was considered as metabolic protective, is redistributed to visceral fat that pose greater metabolic risk as visceral adiposity is more strongly linked with many conditions. However, these age-related changes in BMI should theoretically increase the diabetes risk associated with BMI, rather weaken the association between BMI and diabetes.

Smoking is a concern in the analysis of BMI-diabetes associations, because smoking is associated with decreased body weight and an increased risk of diabetes. ${ }^{36}$ In our study, smoking status was statistically adjusted. The interaction between BMI and smoking status on the risk of incident diabetes was explored, and no statistically significant associations were found. Previous studies have reported that the risk of type 2 diabetes in youth is usually increased in persons with a family history of diabetes. ${ }^{37}$ Similarly, we found that a family history of diabetes is an independent risk factor for type 2 diabetes. However, no interaction between age and family history of diabetes was detected.

In addition to the large sample size, the major strength of our study is that our sample was composed of young, middle and old-aged apparently healthy adults, while participants in many other cohorts tended to be older. Furthermore, the data were collected under standardised conditions, and the study followed uniform procedures performed by trained staff. Laboratory methods were also carefully standardised with rigorous internal and external quality controls. Some limitations also existed in our present study. One limitation of our study is that our analysis was not performed on a representative sample of the population, which limits the generalisability of this study; however, data come from sites in China and age 
range is wide. The results of the current study will have wide applicability for the population in China. We did not distinguish between type 1 and type 2 diabetes in the present study. However, because type 2 diabetes accounts for about $95 \%$ of all diabetes cases, our findings are likely more representative of type 2 diabetes. ${ }^{38}$ In addition, we only measured body weight and height at baseline, which did not evaluated fat distribution and weight changes. Finally, even though we adjusted for an extensive set of confounding factors, residual confounding due to the measurement error in the assessment of confounding factors, unmeasured factors such as physical activity and dietary factors cannot be excluded.

In summary, we demonstrated that BMI is independently associated with an increased risk of incident diabetes in older and younger adults. This information extends our existing knowledge to show BMI has a much greater effect on the incidence of diabetes in younger adults. This novel observation likely helps to explain the emerging epidemic of young-onset diabetes, suggesting that it is driven by weight gain and obesity in China. Strategically, it is crucial to prevent diabetes by controlling risk factors, such as weight gain or excessive weight, particularly in younger adults.

Acknowledgements The authors thank the field investigators for their contribution and the participants for their cooperation.

Contributors All authors approved thefinal version of the manuscript.

Funding This work is supported by grants from the National KeyResearch and Development Program of China (No.2016YFC1304801), Science andtechnology project of Nantong City (MS32016021).

Competing interests None declared.

Patient consent Not required.

Ethics approval This study was approved by the Rich Healthcare Group Review Board, and the information was retrieved retrospectively.

Provenance and peer review Not commissioned; externally peer reviewed.

Data sharing statement Extra data can be accessed via the Dryad data repository at http://datadryad.org/withthedoi:10.5061/dryad.ft8750v.

Open access This is an open access article distributed in accordance with the Creative Commons Attribution Non Commercial (CC BY-NC 4.0) license, which permits others to distribute, remix, adapt, build upon this work non-commercially, and license their derivative works on different terms, provided the original work is properly cited, appropriate credit is given, any changes made indicated, and the use is non-commercial. See: http://creativecommons.org/licenses/by-nc/4.0/.

\section{REFERENCES}

1. Medscape. IDF Atlas: About 415 Million Adults Worldwide Have Diabetes. 2015 (Published 02 Dec 2015).

2. Li MZ, Su L, Liang BY, et al. Trends in prevalence, awareness, treatment, and control of diabetes mellitus in mainland china from 1979 to 2012. Int J Endocrinol 2013;2013:753150.

3. Huo X, Gao L, Guo L, et al. Risk of non-fatal cardiovascular diseases in early-onset versus late-onset type 2 diabetes in China: a crosssectional study. Lancet Diabetes Endocrinol 2016;4:115-24.

4. Li L, Ji L, Guo X, et al. Prevalence of microvascular diseases among tertiary care Chinese with early versus late onset of type 2 diabetes. J Diabetes Complications 2015;29:32-7.

5. Song SH. Emerging type 2 diabetes in young adults. Adv Exp Med Biol 2012;771:51-61.

6. Abdullah A, Peeters A, de Courten M, et al. The magnitude of association between overweight and obesity and the risk of diabetes: a meta-analysis of prospective cohort studies. Diabetes Res Clin Pract 2010;89:309-19.

7. Kalra S. Diabesity. J Pak Med Assoc 2013;63:532-4.

8. Houston DK, Nicklas BJ, Zizza CA. Weighty concerns: the growing prevalence of obesity among older adults. J Am Diet Assoc 2009;109:1886-95.

9. Lindström J, Tuomilehto J. The diabetes risk score: a practical tool to predict type 2 diabetes risk. Diabetes Care 2003;26:725-31.

10. Wilson PW, Meigs JB, Sullivan L, et al. Prediction of incident diabetes mellitus in middle-aged adults: the Framingham Offspring Study. Arch Intern Med 2007;167:1068-74.

11. NCD Risk Factor Collaboration (NCD-RisC). Worldwide trends in body-mass index, underweight, overweight, and obesity from 1975 to 2016: a pooled analysis of 2416 population-based measurement studies in 128.9 million children, adolescents, and adults. Lancet 2017;390:2627-42.

12. Di Angelantonio E, Bhupathiraju S. Body-mass index and allcause mortality: individual-participant-data meta-analysis of 239 prospective studies in four continents. Lancet 2016;388:776-86.

13. Lu JL, Molnar MZ, Naseer A, et al. Association of age and BMI with kidney function and mortality: a cohort study. Lancet Diabetes Endocrinol 2015;3:704-14.

14. Ni Mhurchu C, Parag V, Nakamura M, et al. Body mass index and risk of diabetes mellitus in the Asia-Pacific region. Asia Pac J Clin Nutr 2006;15:127-33.

15. National Bureau of Statistics of China. China statistical yearbook 2011. Beijing: China Statistics Press, 2011

16. Chinese Medical Association Society of Endocrinology Group Obesity. Expert consensus for Chinese adult obesity prevention and control. Chin J Endocrinol Metab 2011;27:711-7.

17. National Diabetes Research Group. A mass survey of diabetes mellitus in a population of 300,000 in 14 provinces and municipalities in China. Zhonghua Nei Ke Za Zhi 1981;20:678-83.

18. Pan XR, Yang WY, Li GW, et al. Prevalence of diabetes and its risk factors in China, 1994. National Diabetes Prevention and Control Cooperative Group. Diabetes Care 1997;20:1664-9.

19. Yang W, Lu J, Weng J, et al. Prevalence of diabetes among men and women in China. N Engl J Med 2010;362:1090-101.

20. $\mathrm{Xu} \mathrm{Y}$, Wang L, He J, et al. Prevalence and control of diabetes in Chinese adults. JAMA 2013;310:948-59.

21. Quan J, Li TK, Pang H, et al. Diabetes incidence and prevalence in Hong Kong, China during 2006-2014. Diabet Med 2017;34:902-8.

22. DECODE Study Group on behalf of the European Diabetes Epidemiology Study Group. Will new diagnostic criteria for diabetes mellitus change phenotype of patients with diabetes? Reanalysis of European epidemiological data. BMJ 1998;317:371-5.

23. Qiao Q, Hu G, Tuomilehto J, et al. Age- and sex-specific prevalence of diabetes and impaired glucose regulation in 11 Asian cohorts. Diabetes Care 2003;26:1770-80.

24. Hartemink N, Boshuizen HC, Nagelkerke NJ, et al. Combining risk estimates from observational studies with different exposure cutpoints: a meta-analysis on body mass index and diabetes type 2 . Am J Epidemiol 2006;163:1042-52.

25. Wang D, Li Y, Lee SG, et al. Ethnic differences in body composition and obesity related risk factors: study in Chinese and white males living in China. PLoS One 2011;6:e19835.

26. Khoo CM, Sairazi S, Taslim S, et al. Ethnicity modifies the relationships of insulin resistance, inflammation, and adiponectin with obesity in a multiethnic Asian population. Diabetes Care 2011;34:1120-6.

27. Canning KL, Brown RE, Jamnik VK, et al. Relationship between obesity and obesity-related morbidities weakens with aging $J$ Gerontol A Biol Sci Med Sci 2014;69:87-92.

28. Ni Mhurchu C, Parag V, Nakamura M, Patel A, Rodgers A, et al. Body mass index and risk of diabetes mellitus in the Asia-Pacific region. Asia Pac J Clin Nutr 2006;15:127-33.

29. Lumeng $C N$, Saltiel AR. Inflammatory links between obesity and metabolic disease. J Clin Invest 2011;121:2111-7.

30. Reinehr T, Karges B, Meissner T, et al. Inflammatory Markers in obese adolescents with type 2 diabetes and their relationship to hepatokines and adipokines. J Pediatr 2016;173:131-5.

31. Vrachnis N, Antonakopoulos N, lliodromiti Z, et al. Impact of maternal diabetes on epigenetic modifications leading to diseases in the offspring. Exp Diabetes Res 2012;2012:1-6.

32. Pettitt DJ, Lawrence JM, Beyer J, et al. Association between maternal diabetes in utero and age at offspring's diagnosis of type 2 diabetes. Diabetes Care 2008;31:2126-30.

33. Dollman J, Norton K, Norton L. Evidence for secular trends in children's physical activity behaviour. Br J Sports Med 2005;39:892-7. Discussion 7. 
34. Gustat J, Srinivasan SR, Elkasabany A, et al. Relation of self-rated measures of physical activity to multiple risk factors of insulin resistance syndrome in young adults: the Bogalusa Heart Study. $J$ Clin Epidemiol 2002;55:997-1006.

35. Cruz-Jentoft AJ, Landi F, Schneider SM, et al. Prevalence of and interventions for sarcopenia in ageing adults: a systematic review. Report of the International Sarcopenia Initiative (EWGSOP and IWGS). Age Ageing 2014;43:748-59.
36. Yeh HC, Duncan BB, Schmidt MI, et al. Smoking, smoking cessation, and risk for type 2 diabetes mellitus: a cohort study. Ann Intern Med 2010;152:10-17.

37. Malecka-Tendera E, Erhardt E, Molnár D. Type 2 diabetes mellitus in European children and adolescents. Acta Paediatr 2005;94:543-6.

38. World Health Organization. Prevention of diabetes mellitus. http:// whqlibdoc.who.int/trs/WHO_TRS_844.pdf (accessed 28 Dec 2012). 